\title{
Microrganismos promotores de crescimento em alface
}

\author{
Samiele Camargo de Oliveira DOMINGUES ${ }^{*}$, Marco Antonio Camillo de CARVALHO2,3, \\ Hudson de Oliveira RABELO ${ }^{3}$, Edmar Santos MOREIRA ${ }^{3}$, Luiz Fernando SCATOLA³, \\ Grace Queiroz DAVID 3
}

\author{
${ }^{1}$ Programa de Pós-Graduação Ecologia e Conservação, Universidade do Estado de Mato Grosso, Nova Xavantina, MT, Brasil. \\ 2Programa de Pós-Graduação Biodiversidade e Agroecossistemas Amazônicos, Universidade do Estado de Mato Grosso, Alta Floresta, \\ MT, Brasil. \\ ${ }^{3}$ Universidade do Estado de Mato Grosso, Alta Floresta, MT, Brasil. \\ *E-mail: samieledomingues@gmail.com \\ (ORCID: 0000-0002-7772-8310; 0000-0003-4966-1013; 0000-0003-1196-6356; 0000-0001-6493-3975; \\ 0000-0001-9329-8317; 0000-0001-6032-8516)
}

Recebido em 18/05/2020; Aceito em 27/01/2021; Publicado em 23/04/2021.

\begin{abstract}
RESUMO: A alface (Lactuca sativa L.) é a hortaliça mais consumida no Brasil, sendo comercializada in natura, o que faz necessário que seja de boa qualidade. Uma alternativa para a redução dos fertilizantes químicos é a utilização de microrganismos promotores de crescimento. Objetivou-se avaliar a eficiência da utilização de microrganismos como promotores de crescimento em cultivares de alface. Empregou-se o delineamento inteiramente casualizado no esquema fatorial 2 × 6, duas cultivares (Mediterrânea e Solaris) sobre a atuação de seis promotores de crescimento (testemunha, três isolados de Trichoderma atroviride, Bacillus subtilis e Azospirillum brasilense), com 6 repetições. Os tratamentos foram aplicados utilizando soluções, em que as raízes ficaram imersas durante uma hora, antes dos transplantio para os vasos. A quantidades de conídios ou estirpes de bactérias nas soluções utilizado foram 4,0x107 por mL-1. Foram avaliadas: número total de folha, comprimento do caule, diâmetro do caule, altura da parte aérea, área foliar, massa fresca total e comercial da parte aérea, comprimento da raiz, massa fresca da raiz, massa seca da parte aérea total, e massa seca da raiz. A utilização dos promotores de crescimento demostrou-se eficiente em ambas cultivares de alface avaliadas. A cultivar Mediterrânea em relação a cultivar Solares foi superior. Entre os tratamentos o que se mostraram mais eficientes foram os com T. atroviride, que proporcionando aumentos significativos na altura total, comprimento de raiz, massa fresca e seca de raiz.
\end{abstract}

Palavras-chave: Azospirillum brasilense; Bacillus subtilis; Lactuca sativa L.; Trichoderma spp.

\section{Microorganisms as growth promoters in lettuce cultivars}

\begin{abstract}
Lettuce (Lactuca sativa L.) is the most consumed vegetable in Brazil, being commercialized in natura, which makes it necessary to be of good quality. An alternative for reducing chemical fertilizers is the use of growth-promoting microorganisms. The objective was to evaluate the efficiency of the use of microorganisms as growth promoters in lettuce cultivars. A completely randomized design was used in the factorial scheme $2 \times 6$, two cultivars (Mediterrânea and Solaris) on the performance of six growth promoters (control, three isolates of Trichoderma atroviride, Bacillus subtilis and Azospirillum brasilense), with 6 replications. The treatments were applied using solutions, in which the roots were immersed for one hour, before transplanting to the pots. The amounts of conidia or strains of bacteria in the solutions used were $4.0 \times 107$ per mL- 1 . The following were evaluated: total leaf number, stem length, stem diameter, shoot height, leaf area, total and commercial shoot weight, root length, fresh root weight, dry shoot weight, and dry root mass. The use of growth promoters proved to be efficient in both evaluated lettuce cultivars. The cultivar Mediterrânea compared to cultivar Solares was superior. Among the treatments that showed to be the most efficient were those with T. atroviride, which provided significant increases in total height, root length, fresh and dry root mass.
\end{abstract}

Keywords: Azospirillum brasilense; Bacillus subtilis; Lactuca sativa L.; Trichoderma spp.

\section{INTRODUÇÃO}

Alface (Lactuca sativa L.) é uma olerícola folhosa que pertence à família Asteraceae. A cultura é popularmente consumida em todo mundo e amplamente cultivada, ocorrendo em praticamente todas as regiões do Brasil, desde que seja respeitado os aspectos de adaptação da cultivar (CARVALHO et al., 2009; BARBOSA et al., 2018).

No Brasil, cultiva-se a alface em campo aberto, ambiente protegido, sistema hidropônico ou orgânico, geralmente pela agricultura familiar em pequenas áreas, normalmente vizinhas aos centros consumidores (cinturões verdes) (TAVARES et al., 2019). A necessidade de fornecimento de produtos in natura de boa qualidade, durante todo o ano faz que seja crescente a busca por novas tecnologias efetivas, de baixo custo e sustentáveis para o manejo da cultura (MAGGI et al., 2006; BARBOSA et al., 2018). 
A alface é altamente dependente do uso de fertilizantes, principalmente em solos tropicais. Neste aspecto, a promoção do crescimento vegetal por microrganismos é uma alternativa viável para diminuição do uso de fertilizantes químicos, mantendo o intuito do aumento da produtividade (BARBOSA et al., 2018; TAVARES et al., 2019). Os microrganismos promotores de crescimento conhecidos (MPCPs), são atóxicos ao homem e animais, possuem custo acessível, e são vantajosos, pois podem persistir no solo ou nas plantas, podendo dispensar reaplicações (BRAND et al., 2007).

Entre os MPCPs encontra-se o gênero Trichoderma spp., fungo imperfeito, pertencente à Sub-divisão Deuteromycotina, ordem Hifomicetes e família Moniliaceae, o qual possui muitas espécies que são geneticamente distintas. Podem facilmente ser encontrados no mundo todo em praticamente todos os solos, presentes na rizosfera. Este gênero está relacionado ao aumento de produtividade, o que faz com que sejam amplamente estudados quanto a capacidade de promoção de crescimento vegetal, por isso há vários produtos comercializados disponíveis (MELO 1991; SAHARAN; NEHRA, 2011; MACHADO et al., 2012; NAWROCKA et al., 2013).

Quanto a utilização de Bactérias Promotoras do Crescimento de Plantas (BPCPs), é uma opção viável para diminuir o custo de produção e o impacto ambiental dos cultivos, é diminuir o uso de adubos nitrogenados e auxiliar nos incrementos de produtividade (MATOSO et al., 2016).

Apesar dos crescentes relatos sobre a promoção de crescimento por MPCPs há uma grande gama de microrganismo que possuem essa capacidade, ainda são escassos estudos desses na produção de olerícolas. Assim, com a finalidade de produzir alface de maneira competitiva e sustentável, dando ênfase à produtividade, qualidade, lucratividade e com um mínimo de impacto ao meio ambiente, buscou-se no presente trabalho avaliar o efeito de microrganismos promotores de crescimentos sobre duas cultivares de alface.

\section{MATERIAL E MÉTODOS}

O experimento foi conduzido no mês de fevereiro de 2019 em ambiente protegido localizado em área experimental da Universidade do Estado de Mato Grosso - Alta Floresta, MT, Brasil. Empregou-se o delineamento inteiramente casualizado no esquema fatorial $2 \times 6$, sendo duas cultivares (BRS Mediterrânea e SVR 06511236 Solaris) na atuação de seis promotores de crescimento (testemunha sem promotores de crescimento (T0), Trichoderma atroviride isolado de couve (Brassica oleracea) (TC), T. atroviride isolado de cogumelo comestível (Pleurotus pulmonarius) (TP), T. atroviride isolado de quiabo (Abelmoschus esculentus) (TQ), Biobac ${ }^{\circledR}$ (Bacillus subtilis) (BS), e Nitro Geo AZ® (Aqospirillum brasilense) (AZ). Cada tratamento contou com 6 repetições, sendo duas mudas por vasos.

As unidades experimentais foram compostas por vasos, com capacidade de 3,0 dm 3, os quais foram preenchidos com substrato na proporção solo e areia 3:1, em que ambos materiais foram esterilizados em autoclave por 90 minutos, a $121{ }^{\circ} \mathrm{C}$ (pressão de $\left.1,0 \mathrm{~atm}\right)$. O solo utilizado foi coletado da camada de 0 a $0,20 \mathrm{~m}$ de profundidade, na zona rural da região de Alta Floresta - MT, sendo caracterizado por Latossolo vermelho-amarelo.

Após a coleta do solo, uma amostra do mesmo foi enviada para análise no laboratório de Análises de Solo,
Adubo e Foliar da Universidade do Estado de Mato Grosso - LASAF, para a determinação das características químicas e granulométricas (Tabela 1), seguindo a metodologia da Embrapa (SILVA, 2009), e apresentou as seguintes características: Argila: 457 g. $\mathrm{kg}^{-1}$; silte: 99 g. $\mathrm{kg}^{-1}$; areia: 644 g.kg-1; $\mathrm{pH}$ em água: 5,6; P: 9,7 $\mathrm{mg} \mathrm{dm}^{-3} ; \mathrm{K}^{-2} 22 \mathrm{mg} \mathrm{dm}^{-3}$; Ca: 4,71 $\mathrm{cmol}_{\mathrm{c}} \mathrm{dm}^{-3}$; $\mathrm{Mg}: 1,13 \mathrm{cmol}_{\mathrm{c}} \mathrm{dm}^{-3}$; SB: $1,73 \mathrm{cmol}_{\mathrm{c}} \mathrm{dm}^{-3}$; V: $78,8 \%$ e CTC: $6,4 \mathrm{cmol}_{\mathrm{c}} \mathrm{dm}^{-3}$.

A adubação e a correção da fertilidade do solo seguiram as recomendações de Malavolta (1981), onde foram utilizados $50 \mathrm{mg} \mathrm{dm}-3$ de N (ureia - 45\% de N), $200 \mathrm{mg} \mathrm{dm}$ 3 de P (Super Fosfato Simples - 18\% P2O5) e 150 mg dm-3 de K (Cloreto de Potássio - 60\% K2O).

As mudas das cultivares (BRS Mediterrânea e SVR 06511236 Solaris) foram produzidas em bandejas de poliestireno expandido com 150 células, utilizando substrato comercial Carolina Soil $\AA$, que é composto por turfa, vermiculita, resíduo orgânico, resíduo orgânico agroindustrial classe A, e calcário. Na semeadura, foram distribuídas duas sementes por célula, procedendo-se desbaste aos cinco dias após a emergência, deixando apenas a plântula maiores. As bandejas foram dispostas em ambiente protegido com irrigação por microaspersão, com $6 \mathrm{~mm}$ de água por dia. $\mathrm{O}$ transplantio para os vasos ocorreu aos 30 dias após a semeadura, quando as mudas apresentavam três folhas definitivas.

Os promotores de crescimento TC, TP e TQ avaliados neste trabalho, são isolados locais de T. atroviride, e fazem parte da coleção do Laboratório de Microbiologia da Universidade do Estado de Mato Grosso (UNEMAT).

As soluções dos isolados dos $T$. atroviride foram preparadas utilizando conídios. Para o preparo, primeiramente foram produzidos esporos dos fungos a partir do colônias do fungo em meio de cultura Batata-dextroseágar (BDA), em placas de Petri $(90 \mathrm{~mm} \varnothing)$, sendo mantidas em câmaras de crescimento do tipo B.O.D (Bilogical Oxygen Demand), regulada para temperatura constante de $25{ }^{\circ} \mathrm{C}$, com variação de $+1{ }^{\circ} \mathrm{C}$, e o fotoperíodo de 12 horas claro/escuro, durante 20 dias. Após esse tempo foi realizado o preparo da suspensão, na qual foi adicionado $10 \mathrm{~mL}$ de água destilada estéril por placa, e com auxílio da alça de Drigalski efetuou-se a fricção sobre o micélio (RODRIGUES et al., 2014).

Após o preparo das soluções, em uma alíquota de $100 \mu \mathrm{L}$ da mesma, foi contabilizado a quantidades de esporos presentes em cada solução, utilizando a câmara de Neubauer, observada em microscópico ótico. A contagem foi realizada no compartimento 'C' $\left(1 \mathrm{~mm}^{2}\right)$ da câmara de Neubauer, após a contagem os dados foram calculados pela equação 1 :

Conídio $\mathrm{mL}^{-1}=\left\{\left\lceil\frac{(\text { Campo 1+Campo2) }}{2}\right\rceil \times 2,5 \times 10^{5}\right\}$

em que: Campo $1=(\mathrm{E} 1+\mathrm{E} 2+\mathrm{E} 3+\mathrm{E} 4+\mathrm{E} 5)$ e Campo $2=$ $(\mathrm{E} 1+\mathrm{E} 2+\mathrm{E} 3+\mathrm{E} 4+\mathrm{E} 5)$

Quanto aos produtos comerciais, utilizou-se a recomendações dos fabricantes para o preparo das soluções. A quantidades de conídios ou estirpes de bactérias foi padrão para todos os tratamentos, sendo 2,5x107 de conídios ou bactérias por $\mathrm{mL}^{-1}$, sendo que para cada tratamento foram preparados $1 \mathrm{~L}$ da solução. O ajuste de esporos e estipes de bactéria para a concentração deseja foi utilizada pela equação 2: 


$$
\mathrm{Ci} \times \mathrm{Vi}=\mathrm{Cf} \times \mathrm{Vf}
$$

em que: $\mathrm{Ci}$ - Concentração inicial da suspensão de esporos (esporos $/ \mathrm{mL}$ ); Vi - Volume inicial da suspensão $(\mathrm{mL})$; Cf Concentração final desejada (esporos $/ \mathrm{mL}$ ); Vf - volume final da suspensão $(\mathrm{mL})$.

Após o preparo das soluções, as raízes das mudas de alface foram imersas por uma hora nos respetivos tratamentos, com os microrganismos, e em seguida transplantadas nos vasos.

Realizou-se as avaliações com 30 dias após o transplantio das mudas. As variáveis avaliadas foram número total de folha, comprimento do caule, diâmetro do caule, altura da parte aérea, área foliar, massa fresca total da parte aérea, massa fresca comercial da parte aérea, comprimento de raiz, massa fresca da raiz, massa seca da parte aérea total, e massa seca da raiz.

O comprimento aéreo e da raiz $(\mathrm{cm})$ ), foi obtido através da determinação da distância entre a base do caule até a extremidade da parte aérea e raiz. As folhas de alface foram contadas, e posteriormente submetidas no determinador de área foliar (modelo LI 3100, LI-COR $®)$ ), para mensuração de área foliar. As determinações do diâmetro e comprimento do caule, foram realizadas com auxílio de paquímetro digital (150 mm - DIGIMESS-100170). Massas verde e seca foram determinadas com auxílio de balança de precisão $(0,0001 \mathrm{~g})$, após secagem dos materiais em estufa de circulação forçada de ar, regulada para $65^{\circ} \mathrm{C}$ até a obtenção massa seca constante.

Os dados obtidos foram submetidos à análise de variância e as médias comparadas pelo teste de Scott Knott a
5\% de probabilidade, utilizando-se o programa Sisvar 4.6 (FERREIRA, 2011).

\section{RESULTADOS}

Conforme resultados obtidos (Tabela 1) para número de folhas, verificou-se diferença significativa somente entre as cultivares, onde a cultivar mediterrânea apresentou maior média. O aumento no número de folhas é desejável, uma vez que pode vir a expandir a área fotossintética e assim elevar o potencial produtivo da cultura (TAVARES et al., 2019).

A diferença entre os promotores de crescimento para o número de folhas pode estar no fato que o sucesso da promoção de crescimento por bioagentes depende das propriedades e mecanismos de ação do organismo, que é complexa, sendo realizada através de interações entre fatores bioquímicos, produção de diversas enzimas, e compostos benéficos (MACHADO et al., 2012).

Em relação à área foliar, não foi observada diferença significativa entre as cultivares, promotores de crescimento, e a interação entre eles.

Quanto à massa fresca da parte aérea comercial e total, não foi verificado diferença entre os níveis dos fatores cultivar e promotor, assim como também não foi observada interação significativa entre os mesmos.

Houve diferença entre as cultivares para massa seca da parte aérea total (Tabela 1), sendo a cultivar Mediterrânea superior à Solaris, em que este resultado reflete o maior número de folhas proporcionada por essa cultivar. Não foi verificada diferença entre os promotores e também interação entre os mesmos para essa cultivar.

Tabela 1. Valores de F e coeficiente de variação CV (\%) de plantas de alface em função de cultivar e tratamentos com microrganismos promotores de crescimento para número de folhas $(\mathrm{NF})$, área foliar (AF), massa fresca da parte aérea comercial (MFCPA), massa fresca total da parte aérea (MFPAT), massa seca da parte aérea total (MSPAT). Alta Floresta - MT (2019).

Table 1. F values and CV variation coefficient (\%) of lettuce plants as a function of cultivar and treatments with growth-promoting microorganisms for number of leaves (NF), leaf area (AF), fresh weight of the commercial shoot (MFCPA), total fresh shoot weight (MFPAT), total dry weight shoot (MSPAT). Alta Floresta - MT (2019).

\begin{tabular}{|c|c|c|c|c|c|}
\hline \multirow{2}{*}{ Cultivar (C) } & $\mathrm{NF}$ & $\mathrm{AF}$ & MFCPA & MFPAT & MSPAT \\
\hline & uni & $\mathrm{mm}^{2}$ & $\mathrm{~g}$ & $\mathrm{~g}$ & $\mathrm{~g}$ \\
\hline Solaris & $11,00 \mathrm{~b}$ & 602,57 & 17,14 & 20,14 & $2,17 \mathrm{~b}$ \\
\hline Mediterrânea & $12,64 \mathrm{a}$ & 663,98 & 18,52 & 21,90 & $2,82 \mathrm{a}$ \\
\hline Valor de F & $21,18^{* *}$ & $3,98 \mathrm{~ns}$ & $1,94 \mathrm{~ns}$ & $1,66 \mathrm{~ns}$ & $9,49 * *$ \\
\hline \multicolumn{6}{|c|}{ Promotores de Crescimento (PC) } \\
\hline T0 & 12,25 & 636,59 & 17,03 & 19,53 & 2,49 \\
\hline TQ & 12,33 & 704,62 & 18,35 & 22,75 & 2,99 \\
\hline $\mathrm{TP}$ & 11,30 & 643,85 & 19,18 & 20,66 & 2,49 \\
\hline $\mathrm{TC}$ & 11,34 & 606,25 & 16,84 & 18,74 & 2,35 \\
\hline BS & 11,38 & 543,48 & 15,96 & 21,75 & 2,14 \\
\hline AZ & 12,32 & 664,86 & 19,63 & 22,72 & 2,52 \\
\hline Valor de F & $1,49 \mathrm{~ns}$ & $2,11 \mathrm{~ns}$ & $1,43 \mathrm{~ns}$ & $1,01 \mathrm{~ns}$ & $1,19 \mathrm{~ns}$ \\
\hline \multicolumn{6}{|c|}{ Interação C x PC } \\
\hline Valor de F & $1,22 \mathrm{~ns}$ & $1,78 \mathrm{~ns}$ & $1,62 \mathrm{~ns}$ & $0,81 \mathrm{~ns}$ & $0,24 \mathrm{~ns}$ \\
\hline CV $(\%)$ & 12,80 & 20,62 & 23,51 & 27,32 & 35,96 \\
\hline
\end{tabular}

Obs. ${ }^{* *}$ e ns correspondem respectivamente a significativo a 1\%, e não significativo de acordo com o teste de Scott-Knott..Médias seguidas de mesma letra, minúscula na coluna, não diferem entre si ano nível de 5\% pelo teste de Scott-Knott. Tratamento: Testemunha (T0), três isolados de Trichoderma atroviride obtidos em quiabo (TQ), Pleurotus pulmonarius (TP), e couve (TC), Bacillus subtilis, (BS) Azospirillum brasilense (AZ).

Na Tabela 2 estão apresentados os desdobramentos da interação significativa entre cultivares e promotores para comprimento do caule (CC), diâmetro do caule (DC), altura da parte aérea (APA), comprimento da raiz (CR), massa fresca da raiz (MFR) e massa seca da raiz.

Para o comprimento do caule, ocorreu diferença somente entre as cultivares para testemunha (T0) e os promotores TP, TQ e AZ. Para a cultivar Solaris, os maiores comprimentos de caule foram verificados em TC e BS. Já a cultivar mediterrânea não foi observada diferença entre os promotores. Esse resultado demonstrou que ocorreu interação entre o material genético utilizado e os promotores.

Não foi observada diferença para o diâmetro de caule, em relação às cultivares somente entre os promotores TC e BS 
(Tabela 2). Os promotores BS e TC proporcionaram maior diâmetro de caule na cultivar Solaris. Já para a cultivar mediterrânea, não foi observada diferença entre os promotores. Foi observada diferença significativa entre as cultivares para altura da parte aérea nos promotores T0, TP, TC e AZ, com maior média em todos da cultivar mediterrânea, indicando que estes promotores não foram capazes de influenciar esta variável, pois não diferiram da testemunha (T0). Os promotores TQ, TC e BS proporcionaram as maiores alturas na cultivar Solaris, já para cultivar Mediterrânea, não foi verificada diferença entre os promotores.

Tabela 2. Desdobramento da interação significativa entre cultivares de alface e agentes de controle para comprimento do caule (CC), diâmetro do caule (DC), altura da parte aérea (APA), comprimento da raiz (CR), massa fresca da raiz (MFR) e massa seca da raiz (MSR). Alta Floresta - MT, (2019).

Table 2. Breakdown of significant interaction between lettuce cultivars and control agents for stem length (CC), stem diameter (DC), shoot height (APA), root length (CR), fresh root weight (MFR) and dry root mass (MSR). Alta Floresta - MT, (2019).

\begin{tabular}{|c|c|c|c|c|c|c|}
\hline \multirow{2}{*}{ Cultivar (C) } & \multicolumn{6}{|c|}{ Promotor de crescimento (PC) } \\
\hline & T0 & TC & TP & TQ & BS & $\mathrm{AZ}$ \\
\hline & \multicolumn{6}{|c|}{ Comprimento do caule $(\mathrm{cm})$} \\
\hline Solaris & $3,15 \mathrm{~b} \mathrm{~B}$ & 4,24 a A & $3,50 \mathrm{~b} \mathrm{~B}$ & $3,30 \mathrm{~b} \mathrm{~B}$ & 4,20 a A & $2,96 \mathrm{~b} \mathrm{~B}$ \\
\hline \multirow{4}{*}{$\begin{array}{l}\text { Mediterrânea } \\
\text { Valor de F 4,61** } \\
\text { CV } 17,65 \%\end{array}$} & 5,29 a A & $4,17 \mathrm{~b} \mathrm{~A}$ & 5,54 a $\mathrm{A}$ & 4,79 b A & $4,50 \mathrm{~b} \mathrm{~A}$ & $4,04 \mathrm{~b} \mathrm{~A}$ \\
\hline & & & & & & \\
\hline & & & & & & \\
\hline & \multicolumn{6}{|c|}{ Diâmetro do caule $(\mathrm{mm})$} \\
\hline Solaris & 10,12 b B & $12,30 \mathrm{a} A$ & $10,96 \mathrm{~b} \mathrm{~B}$ & $10,29 \mathrm{~b} \mathrm{~B}$ & $12,60 \mathrm{a} \mathrm{A}$ & $9,48 \mathrm{~b} \mathrm{~B}$ \\
\hline \multirow{4}{*}{$\begin{array}{l}\text { Mediterrânea } \\
\text { Valor de F 2,45* } \\
\text { CV 10,73\% }\end{array}$} & 12,71 a A & 12,17 a A & 13,13 a A & 12,35 a $\mathrm{A}$ & 13,37 a A & 12,26 a A \\
\hline & & & & & & \\
\hline & & & & & & \\
\hline & \multicolumn{6}{|c|}{ Altura da parte aérea $(\mathrm{cm})$} \\
\hline \multirow{5}{*}{$\begin{array}{l}\text { Solaris } \\
\text { Mediterrânea } \\
\text { Valor de F 8,67** } \\
\text { CV 12,39\% } \\
\end{array}$} & 16,00 a B & 17,66 a $\mathrm{A}$ & 16,90 a B & 18,13 a $\mathrm{A}$ & $17,35 \mathrm{a} \mathrm{A}$ & $8,98 \mathrm{~b} \mathrm{~B}$ \\
\hline & 20,07 a A & $17,40 \mathrm{~b} \mathrm{~A}$ & 20,66 a A & 19,13 a $\mathrm{A}$ & $15,81 \mathrm{~b} \mathrm{~A}$ & $17,60 \mathrm{~b} \mathrm{~A}$ \\
\hline & & & & & & \\
\hline & & & & & & \\
\hline & \multicolumn{6}{|c|}{ Comprimento da raiz $(\mathrm{cm})$} \\
\hline Solaris & 26,38 a A & $20,71 \mathrm{~b} \mathrm{~A}$ & $19,17 \mathrm{~b} \mathrm{~A}$ & 15,05 b B & $20,79 \mathrm{~b} \mathrm{~A}$ & $20,47 \mathrm{~b} \mathrm{~A}$ \\
\hline \multirow{4}{*}{$\begin{array}{l}\text { Mediterrânea } \\
\text { Valor de F 2,56* } \\
\text { CV 22,19\% }\end{array}$} & 20,67 a B & 23,60 a A & 24,48 a A & 21,51 a $\mathrm{A}$ & 22,03 a A & 22,46 a A \\
\hline & & & & & & \\
\hline & & & & & & \\
\hline & \multicolumn{6}{|c|}{ Massa fresca da raiz $(\mathrm{g})$} \\
\hline Solaris & $7,59 \mathrm{~b} \mathrm{~A}$ & 10,24 a A & $7,01 \mathrm{~b} \mathrm{~B}$ & 8,76 a B & 9,60 a A & $6,58 \mathrm{~b} \mathrm{~B}$ \\
\hline \multirow{4}{*}{$\begin{array}{l}\text { Mediterrânea } \\
\text { Valor de F 17,19** } \\
\text { CV } 18,64 \%\end{array}$} & $6,36 \mathrm{c} \mathrm{A}$ & $7,58 \mathrm{c} \mathrm{B}$ & 14,80 a A & 13,57 a A & $10,09 \mathrm{~b} \mathrm{~A}$ & 12,75 a A \\
\hline & & & & & & \\
\hline & & & & & & \\
\hline & \multicolumn{6}{|c|}{ Massa seca da raiz $(\mathrm{g})$} \\
\hline Solaris & 0,90 a A & $1,40 \mathrm{a} \mathrm{A}$ & 0,95 a B & 0,88 a B & 1,23 a $\mathrm{A}$ & 0,83 a $\mathrm{A}$ \\
\hline Mediterrânea & $1,29 \mathrm{~b} \mathrm{~A}$ & $1,63 \mathrm{~b} \mathrm{~A}$ & 3,02 a A & 2,01 a A & $1,25 \mathrm{~b} \mathrm{~A}$ & $1,57 \mathrm{~b} \mathrm{~A}$ \\
\hline Valor de F $3,85^{* *}$ & & & & & & \\
\hline CV $50,26 \%$ & & & & & & \\
\hline
\end{tabular}

Em relação ao comprimento de raiz (Tabela 2), verificouse diferença entre as cultivares em T0, com maior média para cultivar Solaris e em TQ com maior média para cultivar Mediterrânea. Na cultivar Solaris o maior comprimento de raiz foi observado na testemunha $\mathrm{T} 0$, a qual foi superior aos demais promotores. Para a cultivar Mediterrânea, não foi observada diferença entre os promotores evidenciando menor efeito desses nesta cultivar. Para massa fresca de raiz no promotor TC Foi observada diferença significativa entre as cultivares havendo maiores valores de massa para a cultivar Solaris, e nos promotores TP, TQ e AZ, com maior massa para a cultivar Mediterrânea.

Para Solaris, a maior massa fresca de raiz foi observada no promotor TC, o qual não diferiu somente de TQ e BS. A maior massa fresca de raiz para Mediterrânea foi verificada em TP o qual não diferiu de TQ e AZ.

\section{DISCUSSÃO}

Houve diferença para massa seca de raiz entre as cultivares em TP e TQ observando-se superioridade da cultivar
Mediterrânea (Tabela 2). Na cultivar Solaris, a menor massa seca de raiz foi verifica em TQ, já para a cultivar Mediterrânea não se verificou diferença entre os promotores.

Os microrganismos B. subtilis (BS) e T. atroviride (TC), que se destacaram como promotores de crescimento quando utilizada para a cultivar Solaris.

B. subtilis pode favorecer o desempenho de culturas, pois se trata de uma bactéria gram-positiva não patogênica, amplamente utilizada. $\mathrm{O}$ aumento de biomassa segundo Lima (2010) deve-se ao fato desse gênero possuir mecanismos de ação isolados, que apresentam características em promover o crescimento vegetal.

O modo de ação do B. subtilis em estimular o aumento da produtividade nas culturas, possivelmente pode ocorrer devido à capacidade dessas bactérias em atuarem pela produção de fitormônios de crescimento, como auxinas e giberelinas, pectinase ou sinais moleculares, também demonstram que são capazes de elevar a disponibilização do fósforo em estádios mais avançados do desenvolvimento (LANNA FILHO et al., 2010; ZUCARELI et al., 2018). 
De acordo com Mattos et al. (2008), alfaces sobre estresse que são produzidas em temperaturas elevadas, podem ocasionar efeito que alteram seu metabólicos, o que pode levar nos tecidos vegetais a elevação da atividade respiratória e evolução de etileno. O etileno, quando se acumula no interior dos tecidos, promove o aumento da respiração, estimula diversos processos metabólicos e, consequentemente reduz a qualidade dessa hortaliça (HONÓRIO; MORETTI, 2002).

$\mathrm{Na}$ alface, o acúmulo do etileno estimula a paralização do desenvolvimento da raiz, a utilização de bactérias promotoras do crescimento pode estimular o crescimento das plantas atuando na redução dos níveis de etileno através da ação da enzima ACC desaminase, essa redução nas raízes de plantas hospedeiras resultando em seu alongamento (HONÓRIO; MORETTI, 2002; GLICK et al., 1998). A capacidade dos promotores em estimularem o crescimento vegetal pode estar diretamente relacionada à habilidade desses microrganismos em colonizarem e sobreviverem no solo e/ou rizosfera das plantas onde forem introduzidos (MATTOS et al., 2008; HARMAN et al., 2004; CRUZ, 2010). A promoção do crescimento radicular é um dos efeitos benéficos dos MPCPs, pois o estabelecimento rápido de raízes laterais e adventícias é uma característica vantajosa para plantas, aumentando a habilidade de se fixar ao solo e obter água e nutrientes do ambiente (PRIGENT-COMBARET et al., 2008)

Em relação a T. atroviride, Nawrocka (2013), a forma de ação de algumas cepas de Trichoderma sp. está na capacidade de fornecer as plantas nutrientes e fitohormônios, como o ácido indol-acético (AIA), que influência no crescimento das plantas, embora seja mais provável que este gênero de fungo estimule o crescimento por influenciarem no equilíbrio dos hormônios, tais como AIA, ácido giberélico e etileno, interferindo também no seu metabolismo de hidratos de carbono e na fotossíntese, contribuindo para o crescimento de raiz e acumulo de massa.

Os valores obtidos no presente estudo enfatizam a variação de resposta dos três isolados de T. atroviride (TQ, TP e TC) entre as variáveis, podendo deixar claro que o fato de um isolado apresentar bom efeito para um cultivar, não necessariamente detém um potencial positivo para a outra. Hoyos-Carvajal et al. (2009) avaliaram a produção de metabólitos de 101 isolados de Trichoderma spp. na Colômbia e verificaram que $20 \%$ das cepas foram capazes de produzir formas solúveis de fosfato de rocha fosfática, sendo que $8 \%$ das amostras avaliadas demonstraram capacidade de produzir sideróforos consistentes para converter ferro a formas solúveis, 60\% produziram ácido indol-3-acético (IAA) ou análogos a auxina, este resultado demostra a singularidades das cepas, o que as podem estar distinguindo como promotores de crescimento.

Outro tratamento que contribuiu com o aumento da massa fresca de raiz foi $\mathrm{AZ}$, sendo que o uso de rizobactérias, em destaque encontra-se o gênero Azospirillum (CANESCHI et al., 2019), um microrganismo com potencial de promotor do crescimento das plantas (PGPR) (ARAÚJO, 2008). De acordo com Sahariana e Nehra (2011), esse grupo de rizobactérias colonizam de forma agressiva as raízes das plantas, fornecendo crescimento através de vários efeitos, como estimulantes do crescimento radicular.

A resposta positiva para os isolados locais de T. atroviride, se faz importante para a obtenção de novas estirpes, com maior capacidade de promover o crescimento, porque os mecanismos de ação dos PGPR são específicos e podem variar conforme a cultura e o ambiente, como a interferência de outros microrganismos, substrato, temperatura e umidade (LIMA, 2010). Por isso a contribuição de se estudar espécies promotores locais já adaptadas à região podem favorecer ainda mais resposta positiva entre relação 'MicrorganismoPlanta-Ambiente'.

\section{CONCLUSÕES}

A utilização dos promotores de controle se demostra eficiente para promover o crescimento vegetal para ambas cultivares de alface avaliadas. Entre os promotores de crescimento, o que se mostraram mais eficientes foram os isolados de T. atroviride (TC e TQ), proporcionando diferença entre as cultivares. A cultivar Mediterrânea, teve maior quantidade de folhas, massa seca total da parte aérea, e comprimento de raiz, foi superior a Solares em relação à massa fresca de raiz, quando utilizado os tratamentos $T$. atroviride (TC e TQ), Azospirillum brasilense e Bacillus subtilis. A cultivar Solaris teve aumento no comprimento do caule, diâmetro do caule, e altura da parte aérea, e foi superior para à massa seca da raiz, quando utilizou os $T$. atroviride (TC e TQ).

\section{AGRADECIMENTOS}

À Universidade do Estado de Mato Grosso (Unemat), e a Coordenação de Aperfeiçoamento de Pessoal de Nível Superior (CAPES) pela concessão de bolsa de mestrado do primeiro autor.

\section{REFERÊNCIAS}

ARAÚJO, F. F. Inoculação de sementes com Bacillus subtilis formulado com farinha de ostras e desenvolvimento de milho, soja e algodão. Ciência e Agrotecnologia, Lavras, v. 32, n. 2, p. 456-462, 2008. DOI: 10.1590/S1413-70542008000200017.

BARBOSA, J.; OLIVEIRA, J.; BARBOSA, J.; MARTINS FLHO, A.; MEDEIROS, E.; KUKLINSKY-SOBRAL, J. Influência de esterco bovino e microrganismo promotores de crescimento na cultura da Alface (Lactuca sativa L.), no município de Garanhuns, PE. Cadernos de Agroecologia, Porto Alegre, v. 13, n. 1, p. 1-7, 2018.

BRAND, S. C.; MANZONI, C. G.; JUNGES, E.; DURIGON, M. R.; MILANESI, P.; BLUME, E.; MUNIZ, M. F. B. Extrato de cancorosa (Maytenus ilicifolia) não inibe Trichoderma sp. Revista Brasileira de Agroecologia, Porto Alegre, v. 2, n. 2, p. 1-4, 2007.

CANESCHI, W. L.; SANCHEZ, A. B.; PEREIRA, J. G.; GARCIA, C. C. M.; MOREIRA, L. M. Isolamento e purificação de sideróforos bacterianos: uma abordagem educacional multidisciplinar. Revista de Ensino de Bioquímica, v.17, n. (especial), p. 61-73, 2019.

CARVALHO FILHO, J. L. S. de; GOMES, L. A. A.; MALUF, W. R. Tolerância ao florescimento precoce e características comerciais de progênies F4 de alface do cruzamento Regina 71 x Salinas 88. Acta Scientiarum Agronomy, Maringá, v. 31, n. 1, p. 37-42, 2009. DOI: 10.4025/actasciagron.v31i1.6607.

CRUZ, J. L. G. D. Efeito de Trichoderma spp. no potencial fisiológico de sementes e mudas de melão. 2010. 67p. (Dissertação) - Universidade Federal de Santa Maria, Santa Maria, 2010.

FERREIRA, D. F. Sisvar: um sistema computacional de 
análise estatística. Ciência e Agrotecnologia, Lavras, v. 35, n. 6, p. 1039-1042, 2011. DOI: 10.1590/S141370542011000600001.

GLICK, B. R.; PENROSE, D. M.; LI, J. A model for the lowering of plant ethylene concentrations by plant growth-promoting bacteria. Journal of Theoretical Biology, Amsterdam, v. 190, n. 1, p. 63-68, 1998. DOI: 10.6064/2012/963401.

HARMAN, G. E.; HOWELL, C. R.; VITERBO, A.; CHET, I.; LORITO, M. Trichoderma species-opportunistic, avirulent plant symbionts. Nature Review Microbiology, v. 2, n. (s/n), p. 43-56, 2004.

HONÓRIO, S. L.; MORETTI, C. L. Fisiologia pós-colheita de frutas e hortaliças. In: CORTEZ LAB, HONÓRIO SL, MORETTI CL. Resfriamento de frutas e hortaliças, Brasília, v. 1, n. (s.n.), 2002. p. 60-94.

HOYOS-CARVAJAL, L.; ORDUZ, S.; BISSETT, J. Growth stimulation in bean (Phaseolus vulgaris L.) by Trichoderma. Biological Control, v. 51, n. 3, p. 409-416, 2009. DOI: 10.1016/j.biocontrol.2009.07.018.

LANNA FILHO, R.; FERRO, H. M.; PINHO, R. S. C. Controle biológico mediado por Bacillus subtilis. Revista Trópica: Ciências Agrárias e Biológicas, Lavras, v. 4, n. 2, p. 12-20, 2010. DOI: 10.0000/rtcab.v4i2.145.

LIMA, F. F. Bacillus subtilis e níveis de nitrogênio sobre o desenvolvimento e a produtividade do milho. 2010. 54p. (Dissertação) - Universidade Federal do Piauí, Teresina, 2010.

MACHADO, D. F. M.; PARZIANELLO, F. R.; SILVA, A. C. F.; ANTONIOLLI, Z. I. Trichoderma no Brasil: o fungo e o bioagente. Revista de Ciências Agrárias, Belém, v. 35, n. 1, p. 274-288, 2012.

MAGGI, M. F.; KLAR, A. E.; JADOSKI, C. J.; ANDRADE, A. R. S. Produção de variedades de alface sob diferentes potenciais de água no solo em ambiente protegido. Irriga, Botucatu, v. 11, n. 3, p. 415-427, 2006.

MALAVOLTA, E. Manual de química agrícola: adubos e adubação. 3 ed. São Paulo: Agronômica Ceres, 1981. 594p.

MATOSO, E. S.; DE MARCO, E.; BELlÉ, C., RODRIGUES, T. A.; DOS ANJOS, S. D. Desenvolvimento inicial de mudas pré-brotadas de canade-açúcar inoculadas com bactérias diazotróficas. Revista da Jornada de Pós-Graduação e PesquisaCongrega Urcamp, v. 13, n. 1, p. 412-434, 2016.

MATTOS, L. M.; MORETTI, C. L.; CHITARRA, A. B.; CHITARRA, M. I. F. Atividade respiratória e evolução de etileno em alface crespa minimamente processada armazenada sob duas temperaturas. Ciência e Agrotecnologia, Lavras, v. 32, n. 6, p. 1985-1990, 2008. DOI: $10.1590 /$ S1413-70542008000600044.
MELO, I. S. Potencialidades de utilização de Trichoderma spp. no controle biológico de doenças de plantas. In: BETTIOL. W. (Org) Controle biológico de doenças de plantas. Jaguariúna: EMBRAPA-CNPMA. 1991. p. 135-156.

NAWROCKA, J.; MAŁOLEPSZA, U. Diversity in plant systemic resistance induced by Trichoderma. Biological Control, v. 67, n. 2, p. 149-156, 2013. DOI: 10.1016/j.biocontrol.2013.07.005.

PRIGENT-COMBARET, C.; BLAHA, D.; POTHIER, J. F.; VIAL, L.; POIRIER, M. A.; WISNIEWSKI-DYÉ, F.; MOËNNE-LOCCOZ, Y. Physical organization and phylogenetic analysis of acdR as leucineresponsive regulator of the 1-aminocyclopropane-1-carboxylate deaminase gene acdS in phytobeneficial Azospirillumlipoferum 4B and other Proteobacteria. FEMS Microbiology Ecology, Hoboken, v. 65, n. 1, p. 202-219, 2008. DOI: 10.1111/j.1574-6941.2008.00474.x.

RODRIGUES, C. Uso de extrato pirolenhoso de Teca (Tectona grandis) no controle alternativo in vitro de Colletotrichum gloeosporioides. 2014. 74p. (Dissertação) - Universidade do Estado de Mato Grosso, Alta Floresta, 2014.

SAHARAN, B. S.; NEHRA, V. Plant growth promoting rhizobacteria: a critical review. Life Sciences and Medicine Research, v. 21, n. 1, p. 30, 2011.

SILVA, F. C. D. S. (Ed.). Manual de análises químicas de solos, plantas e fertilizantes. vol. 627. Brasília: Embrapa Informação Tecnológica; Rio de Janeiro: Embrapa Solos. 2009. 627p.

TAVARES, A. T.; VAZ, J. C.; HAESBAERT, F. M.; REYES, I. D. P.; ROSA, P. H. L.; FERREIRA, T. A.; NASCIMENTO, I. R. Adubação NPK como promotor de crescimento em alface. Agri-Environmental Sciences, v. 5, n. (s/n), p. 1-9, 2019. DOI: 10.36725/agries.v5i0.1215.

ZUCARELI, C.; BARZAN, R. R.; SILVA, J. B.; CHAVES, D. P. Associação de fosfatos e inoculação com Bacillus subtilis e seu efeito no crescimento e desempenho produtivo do feijoeiro. Revista Ceres, Viçosa, v. 65, n. 2 , p. 1793-1802, 2018. DOI: 10.5433/16790359.2011v32Suplp1793. 